\title{
A Novel Mechanism for the Facilitation of Theta-Induced Long-Term Potentiation by Brain-Derived Neurotrophic Factor
}

\author{
Enikö A. Kramár, ${ }^{1}$ Bin Lin, ${ }^{1}$ Ching-Yi Lin, ${ }^{2}$ Amy C. Arai, ${ }^{3}$ Christine M. Gall, ${ }^{2}$ and Gary Lynch ${ }^{1}$ \\ ${ }^{1}$ Department of Psychiatry and Human Behavior, University of California, Irvine, California 92612-1695, ${ }^{2}$ Department of Anatomy and Neurobiology, \\ University of California, Irvine, California 92697-1275, and 3Department of Pharmacology, Southern Illinois University School of Medicine, Springfield, \\ Illinois 62794-9629
}

\begin{abstract}
Brain-derived neurotrophic factor (BDNF) contributes to the induction of long-term potentiation (LTP) by theta-pattern stimulation, but the specific processes underlying this effect are not known. Experiments described here, using BDNF concentrations that have minor effects on baseline responses, show that the neurotrophin both reduces the threshold for LTP induction and elevates the ceiling on maximal potentiation. The enhanced LTP proved to be as stable and resistant to reversal as that recorded under control conditions. BDNF markedly increased the facilitation of burst responses that occurs within a theta train. This suggests that the neurotrophin acts on long-lasting events that (1) are set in motion by the first burst in a train and (2) regulate the amplitude of subsequent bursts. Whole-cell recordings established that BDNF causes a rapid reduction in the size of the long-lasting afterhyperpolarization (AHP) that follows individual theta bursts. Apamin, an antagonist of type 2 small-conductance $\mathrm{Ca}^{2+}$-activated potassium (SK2) channels, also reduced hippocampal AHPs and closely reproduced the effects of BDNF on theta-burst responses and LTP. The latter results were replicated with a newly introduced, highly selective inhibitor of SK2 channels. Immunoblot analyses indicated that BDNF increases SK2 serine phosphorylation in hippocampal slices. These findings point to the conclusion that BDNF-driven protein kinase cascades serve to depress the SK2 component, and possibly other constituents, of the AHP. It is likely that this mechanism, acting with other factors, promotes the formation and increases the magnitude of LTP.
\end{abstract}

Key words: calcium-dependent potassium channels; afterhyperpolarization; phosphorylation; apamin; Lei-Dab ${ }^{7}$; hippocampus; neurotrophin

\section{Introduction}

A considerable body of evidence indicates that brain-derived neurotrophic factor (BDNF) facilitates the formation of longterm potentiation (LTP) and that this effect is separate from its more broadly studied actions on gene expression. Brief applications of BDNF, but not other neurotrophins, to hippocampal or cortical slices allow suboptimal bursts of afferent stimulation to induce robust and stable potentiation (Akaneya et al., 1997; Huber et al., 1998; Kovalchuk et al., 2002). Consistent with this, function-blocking antibodies against the TrkB receptor for BDNF disrupt the formation of stable LTP when applied before or immediately after the delivery of theta-burst stimulation (TBS) but not tetanic stimulation (Kang et al., 1997; Chen et al., 1999; Kossel et al., 2001). The results with antagonists strongly suggest that endogenous BDNF contributes to LTP induction by

Received 0ct. 28, 2003; revised April 14, 2004; accepted April 15, 2004.

This work was supported by National Institute of Neurological Disorders and Stroke Grant NS045260 (G.L. and C.M.G.). We thank Dr. George Chandy for his generous gift of Lei-Dab ${ }^{7}$ and Dr. Hans-Günther Knaus for providing antisera to SK2.

Correspondence should be addressed to Enikö A. Kramár, University Research Park, University of California, 101 Theory Drive, \#250, Irvine, CA 92612-1695. E-mail: ekramar@uci.edu.

DOI:10.1523/JNEUROSCI.0800-04.2004

Copyright $\odot 2004$ Society for Neuroscience $\quad$ 0270-6474/04/245151-11\$15.00/0 naturalistic patterns of afferent activity. Work with mutant mice confirms the link between BDNF and LTP. The magnitude and frequency of potentiation are significantly reduced by deletions in the BDNF coding sequence (Korte et al., 1995) in a manner that is reversed by BDNF infusions (Patterson et al., 1996) or viral-mediated gene transfer (Korte et al., 1996).

There are conflicting results regarding the mechanisms by which BDNF promotes potentiation. LTP is impaired in mice with a generalized reduction in TrkB expression but not when reduced expression is restricted to postsynaptic neurons (Xu et al., 2000). In addition, LTP is readily generated in TrkB-deficient mice using stimulation paradigms that do not require presynaptic mobilization of the transmitter (Xu et al., 2000). Other work indicates that BDNF influences the frequency-following characteristics of synapses in immature slices (Gottschalk et al., 1998; Pozzo-Miller et al., 1999). Together, these results lead to the conclusion that BDNF, via TrkB, sustains release during repetitive stimulation, thereby generating postsynaptic depolarization of sufficient magnitude to unblock NMDA receptors. However, the argument is complicated by reports that BDNF also acts on postsynaptic targets with links to LTP (Manabe, 2002). Postsynaptic densities are enriched in full-length TrkB receptors (Aoki et al., 2000), and exogenous BDNF increases NMDA receptor phos- 
phorylation (Lin et al., 1998; Di Luca et al., 2001) and currents (Song et al., 1998; Crozier et al., 1999; Levine and Kolb, 2000). Although there is disagreement about the magnitude of the effect, BDNF is also reported to decrease IPSCs (Tanaka et al., 1997; Frerking et al., 1998; Cheng and Yeh, 2003), an effect that would be expected to promote LTP induction (Larson et al., 1986). Finally, recent work using applications restricted to small dendritic fields indicates that the neurotrophin increases spine calcium levels via a set of postsynaptic actions (Kovalchuk et al., 2002; Manabe, 2002).

The present study reexamined the effects of BDNF on theta burst-induced LTP, first by asking whether the neurotrophin lowers the threshold and/or raises the ceiling for potentiation. Beyond its significance in arguments about the computational significance of enhancing LTP (Ambros-Ingerson et al., 1990; Carpenter and Milenova, 2002), the generally unexamined issue of threshold versus ceiling is of importance because of differences in the factors that regulate the two variables (Arai and Lynch, 1992; Arai et al., 1994, 2004). Following from these results, additional experiments tested predictions regarding the effects of BDNF on particular physiological and biochemical events associated with LTP induction. This effort led to the identification of a novel and specific mechanism whereby low concentrations of BDNF can potently influence LTP.

\section{Materials and Methods}

All animal procedures were conducted in accordance with the National Institutes of Health Guide for the Care and Use of Laboratory Animals and with protocols approved by the Institutional Animal Care and Use Committee of the University of California at Irvine. This includes efforts to minimize animal suffering and numbers of rats used in the work described.

Slice preparation and recording techniques. All studies used young adult (30- to 42-d-old) male Sprague Dawley rats (Charles River Laboratories, Wilmington, MA). For slice preparation, animals were deeply anesthetized with halothane (Sigma, St. Louis, MO) and then decapitated. The brain was removed quickly and placed in ice-chilled oxygenated dissection medium containing the following (in $\mathrm{mm}$ ): $124 \mathrm{NaCl}, 3 \mathrm{KCl}, 1.25$ $\mathrm{KH}_{2} \mathrm{PO}_{4}, 5 \mathrm{MgSO}_{4}, 3.4 \mathrm{CaCl}_{2}, 26 \mathrm{NaHCO}_{3}$, and 10 glucose. Transverse hippocampal slices $(350 \mu \mathrm{m})$ through the middle third of the septotemporal axis of the hippocampus were prepared using a McIlwain tissue chopper and immediately transferred to an interface recording chamber containing preheated artificial CSF (aCSF) composed of the following (in $\mathrm{mm}): 124 \mathrm{NaCl}, 3 \mathrm{KCl}, 1.25 \mathrm{KH}_{2} \mathrm{PO}_{4}, 2.5 \mathrm{MgSO}_{4}, 3.4 \mathrm{CaCl}_{2}, 26 \mathrm{NaHCO}_{3}$, and 10 glucose (maintained at $31 \pm 1{ }^{\circ} \mathrm{C}$ ) (Kramár et al., 2002). Slices were perfused continuously with this solution at a rate of $2.0-2.5 \mathrm{ml} /$ min, whereas the surface of the slices was exposed to warm, humidified $95 \% \mathrm{O}_{2}-5 \% \mathrm{CO}_{2}$. Recordings began after at least $1.5 \mathrm{hr}$ of incubation.

Field EPSPs (fEPSPs) were recorded from stratum radiatum of CAlb using a single glass pipette filled with $0.15 \mathrm{M} \mathrm{NaCl}$ (yielding a resistance of 2-3 M $\Omega$ ) in response to orthodromic stimulation (twisted nichrome wires, $65 \mu \mathrm{m}$ ) of the Schaffer collateral-commissural projections in CA1 stratum radiatum. Pulses were delivered to the stimulation electrode at $0.05 \mathrm{~Hz}$ with current test intensity adjusted to obtain $50-60 \%$ of the maximum fEPSP. After establishing a 10-20 min stable baseline, test compounds (see below) were introduced into the infusion line by switching from control aCSF to drug-containing aCSF. To determine the LTP threshold and ceiling effect in BDNF-treated slices, the number of theta bursts delivered to induce LTP varied from $2,5,10$, or 20 , with each burst consisting of four pulses at $100 \mathrm{~Hz}$ and the bursts themselves separated by $200 \mathrm{msec}$ (i.e., TBS). The stimulation intensity was not increased during TBS. In some experiments, attempts to reverse potentiation were initiated 30 min after LTP induction to determine the degree of LTP consolidation. Reversal stimulation involved delivering low-frequency theta pulses at $5 \mathrm{~Hz}$ [theta-pulse stimulation (TPS)] for $1 \mathrm{~min}$. Three trains were used with an intertrain interval set at $1 \mathrm{~min}$. Data were collected and digitized by NAC 2.0 Neurodata Acquisition System (Theta Burst, Irvine, $\mathrm{CA}$ ) and stored on a disk.

For whole-cell recording, hippocampal slices were prepared using a vibrating tissue slicer (VT1000; Leica, Bannockburn, IL) and placed in a holding chamber for at least $2 \mathrm{hr}$ before being transferred to a recording chamber. The slices were submerged in oxygenated aCSF containing the following (in mM): $124 \mathrm{NaCl}, 3 \mathrm{KCl}, 1.25 \mathrm{KH}_{2} \mathrm{PO}_{4}, 3.4 \mathrm{CaCl}_{2}, 2.5 \mathrm{MgSO}_{4}$, $26 \mathrm{NaHCO}_{3}$, and $10 \mathrm{D}$-glucose. Except when noted, $50 \mu \mathrm{m}$ picrotoxin (PTX) was added to block $\mathrm{GABA}_{\mathrm{A}}$ currents. The aCSF was equilibrated with $95 \% \mathrm{O}_{2}-5 \% \mathrm{CO}_{2}, \mathrm{pH} 7.3$, and infused at $1.2 \mathrm{ml} / \mathrm{min}$. All experiments were performed at $32^{\circ} \mathrm{C}$.

CA1b pyramidal neurons were visualized with an infrared microscope (BX50WI; Olympus Optical, Melville, NY) with differential interference contrast configuration, and whole-cell recordings were made with 3-5 $\mathrm{M} \Omega$ recording pipettes containing the following (in $\mathrm{mm}$ ): $140 \mathrm{~K}^{+}$gluconate, 2 ATP, 0.4 GTP, and 10 HEPES, pH 7.35 (290-300 mOsm). Patch electrodes were made from borosilicate glass using a Sutter Flaming-Brown horizontal puller (P-87; Sutter Instruments, Novato, CA). Synaptic responses were recorded with a patch amplifier (AxoPatch-1D; Axon Instruments, Union City, CA) with a four-pole low-pass Bessel filter at $2 \mathrm{kHz}$ and digitized at $1-10 \mathrm{kHz}$ with pClamp 7 acquisition software (Axon Instruments). A bipolar stimulating electrode was placed in the stratum radiatum on one side of the recording locus. During current-clamp recordings, membrane potential was maintained at -60 $\mathrm{mV}$ with either hyperpolarizing or depolarizing current injections. The afterhyperpolarization (AHP) was generated by stimulating the Schaffer collateral-commissural projections with a single theta burst (four pulses at $100 \mathrm{~Hz}$ ) every $4 \mathrm{~min}$. The stimulation intensity was adjusted as needed to reliably elicit action potentials. Input and series resistances were continuously monitored, and recordings were discarded if significant changes occurred. Experimental treatments were initiated after a stable baseline of 15 min had been collected.

Drug application. The perfusion system used for drug application during field recordings consisted of chemically inert infusion lines (silicon tubing) connected to a $60 \mathrm{ml}$ syringe. Flow was induced by gravity, and rate was controlled with an intravenous regulator. BDNF (Chemicon, Temecula, CA) stock and the $\mathrm{GABA}_{\mathrm{A}}$ antagonist PTX (Sigma) were prepared fresh on a daily basis in aCSF before being added to the infusion line. Apamin was dissolved in 5\% acetic acid to produce a $1 \mathrm{~mm}$ stock 


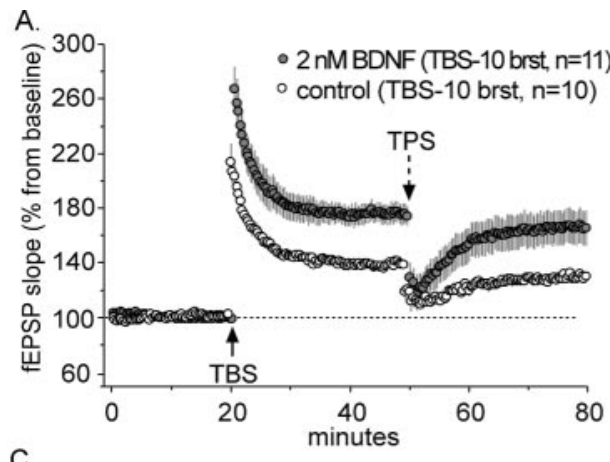

B.
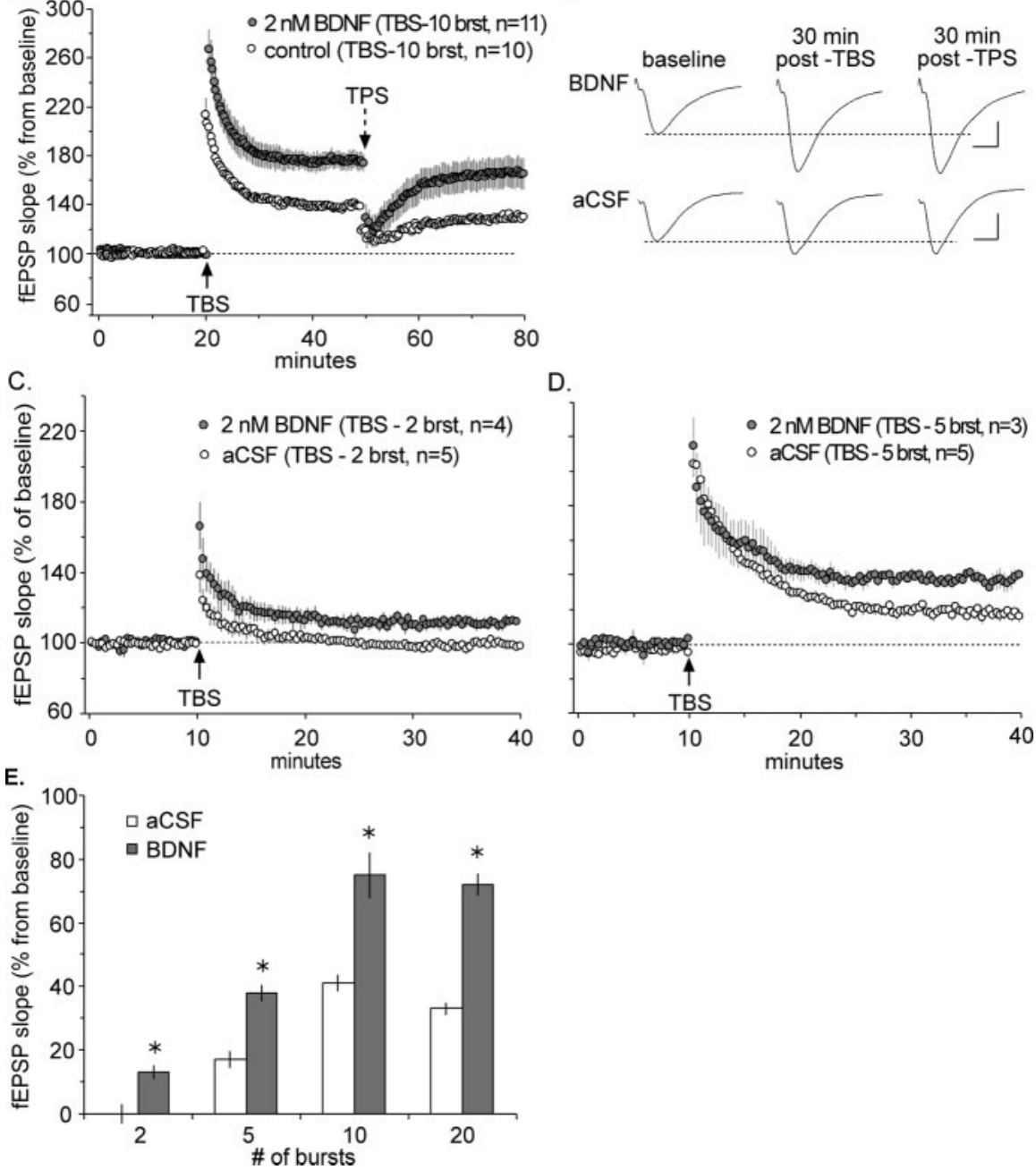

Figure 2. BDNF lowers the threshold and raises the ceiling of LTP induced by theta bursts. The slope of the field EPSP (mean \pm SEM) was normalized to the mean of the last 60 responses collected in the presence of $2 \mathrm{~nm}$ BDNF before application of TBS (upward arrow). $A, A$ train of 10 theta bursts produced a significantly greater degree of $L T P$ in slices treated with BDNF than in control slices. At 30 min after LTP induction, three 1 min trains of $5 \mathrm{~Hz}$ stimulation (TPS, downward arrow), with the trains separated by $1 \mathrm{~min}$, were delivered to the potentiated pathways. The theta-pulse stimulation caused a transient depression of LTP but this recovered over the subsequent $15 \mathrm{~min}$. There were no evident differences in control and BDNF-treated slices with regard to recovery. $B$, Representative traces recorded from control and BDNF-treated slices during baseline, $30 \mathrm{~min}$ after TBS, and $30 \mathrm{~min}$ after TPS. Calibration: $1 \mathrm{mv}, 5 \mathrm{msec}$. C, One pair of theta bursts was sufficient to induce LTP in BDNF-treated slices but not in control slices. D, A train of five theta bursts is twice as effective in inducing LTP in BDNF-treated slices as it is in controls. Note that the degree of potentiation in the former case is approximately equal to that generated by 10 bursts in control slices $(A)$. E, Summary of grouped data (mean \pm SEM) illustrating the effects of BDNF on the level of potentiation produced 30 min after applying 2, 5, 10, and 20 theta bursts. For each treatment, the BDNF group had significantly greater potentiation than the control slices $\left({ }^{*} p<0.001\right)$.

solution and stored at $-8^{\circ} \mathrm{C}$ until further use. On the day of the experiment, apamin was further diluted in aCSF to a final working concentration containing $0.005-0.01 \%$ acetic acid. This working concentration did not influence the $\mathrm{pH}$ (7.35) of aCSF. The specific SK2 calciumactivated potassium channel antagonist Leirotoxin I with diaminobutanoic acid substituting for a met $^{7}\left(\right.$ Lei-Dab ${ }^{7}$ ) (Shakkottai et al., 2001) was prepared in aCSF containing $0.1 \%$ bovine serum albumin and was given as a generous gift by Dr. George Chandy (University of California, Irvine, CA).

For whole-cell recording, BDNF was applied through a glass micropipette (pipette concentration, $20 \mathrm{~nm}$ ) placed within stratum radiatum at the same distance from the cell- body layer as the stimulation electrode. Drug application pipettes had a tip diameter of $\sim 25 \mu \mathrm{m}$ and were prepared by gently tapping the tips of regular patch electrodes. The drug solution was ejected once every $2-3 \mathrm{sec}$, at a pressure of $2-4 \mathrm{psi}$ and with a pulse duration of $56 \mathrm{msec}$, using a Picospritzer (General Valve, Fair- field, NJ). Phenol Red dye was included in the pipette to monitor the spread of the solution.

Data analysis. All electrophysiological data in the text are presented as means $\pm \mathrm{SD}$, and the fEPSP slope was measured at $10-90 \%$ fall of the slope. Data in figures representing drug effects on LTP were normalized to the last $10 \mathrm{~min}$ of drug infusion. A Student's $t$ test was used to compare groups unless otherwise noted. The level of significance was assessed at $p<0.05$. Data were collected from control slices in parallel with experimental tissue for each treatment tested. At the end of the study, measurements from control slices were pooled and used as the comparison to drug-treated slices. Measurements recorded from individual bursts within a train of 10 burst responses included burst area, duration of the burst response, and amplitude of the afterpositivity of the burst response. Areas of bursts $2-10$ were expressed as a percentage change from the initial theta burst. The duration of each burst response was measured by the time (in milliseconds) it took for the repolarization phase of each burst in a train to return to a baseline established during the 10 msec period preceding stimulation. The durations of bursts $2-10$ were then normalized to the duration of the first theta burst. The amplitude of the afterpositivity (in millivolts) was calculated by subtracting the last $10 \mathrm{msec}$ of each burst from a $10 \mathrm{msec}$ baseline period preceding burst stimulation. The sample size for all experiments represents the number of animals used.

Immunoprecipitation and immunoblotting. Coimmunoprecipitation techniques were used to evaluate the effects of BDNF on serine phosphorylation of SK2 channel proteins. Acute hippocampal slices were prepared and treated with $2 \mathrm{ng} / \mathrm{ml}$ BDNF or vehicle as described above. After $1 \mathrm{hr}$, paired groups of slices treated with BDNF or vehicle $(n=10$ slices per group per experiment) were harvested and rapidly frozen. At the time of processing, the slices within a given treatment group were pooled, homogenized in radioimmunoprecipitation assay (RIPA) buffer containing $10 \mathrm{~mm}$ Tris, $\mathrm{pH}$ 7.2, $158 \mathrm{~mm} \mathrm{NaCl}, 1$ mм EDTA, 0.1\% SDS, $1 \%$ sodium deoxycholate, $1 \%$ Triton X-100, Complete Protease Inhibitor Cocktail (Roche Diagnostics, Indianapolis, IN), and Phosphatase Inhibitor Cocktails 1 and 2 (P2850 and 5726; Sigma). After this, the samples were assayed (Bio-Rad, Hercules, CA), normalized for protein content, and then incubated with rabbit anti-phosphoserine (2.5 $\mu \mathrm{g} / \mathrm{ml}$; AB1603; Chemicon) or rabbit anti-SK2 (2 $\mu \mathrm{g} / \mathrm{ml}$; APC-028; Alomone Labs, Jerusalem, Israel) overnight at $4^{\circ} \mathrm{C}$. Immunocomplexes were harvested by the addition of protein A agarose $(80 \mu \mathrm{l} / \mathrm{ml}$; Upstate Biotechnology, Lake Placid, NY) for $2 \mathrm{hr}$ at $4^{\circ} \mathrm{C}$ and centrifugation within Spin Filters and Collection Tubes (CytoSignal, Irvine, CA). After two washes with RIPA buffer and one with Tris-buffered saline (in mM: 150 $\mathrm{NaCl}$ and 10 Tris- $\mathrm{Cl}, \mathrm{pH} 7.4$ ), the immunoprecipitates were eluted in reducing sample buffer, separated by $4-12 \%$ SDS PAGE, and processed for immunoblot analysis of SK2 immunoreactivity using the ECL-plus system from Amersham Biosciences (Arlington Heights, IL), as described in detail previously (Kramár et al., 2002). Two different SK2 antisera were used to probe Western blots: rabbit anti-SK2 from Alomone Labs (APC-028) (Desai et al., 2000) and rabbit anti-SK2 provided by Hans-Günther Knaus (University of Innsbruck, Innsbruck, 
A.
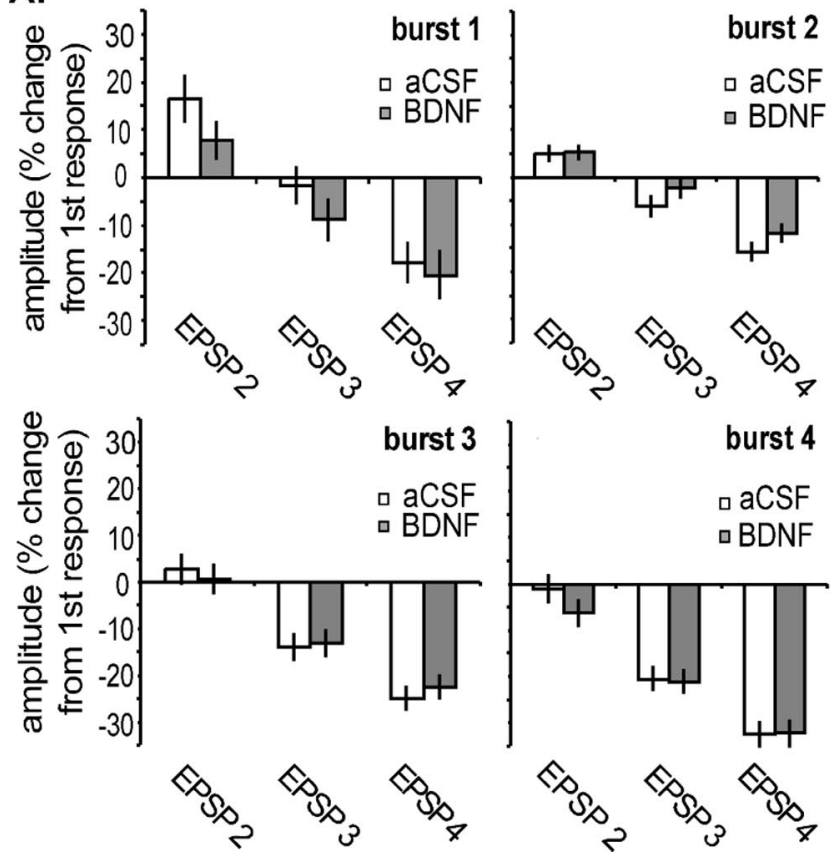

B.
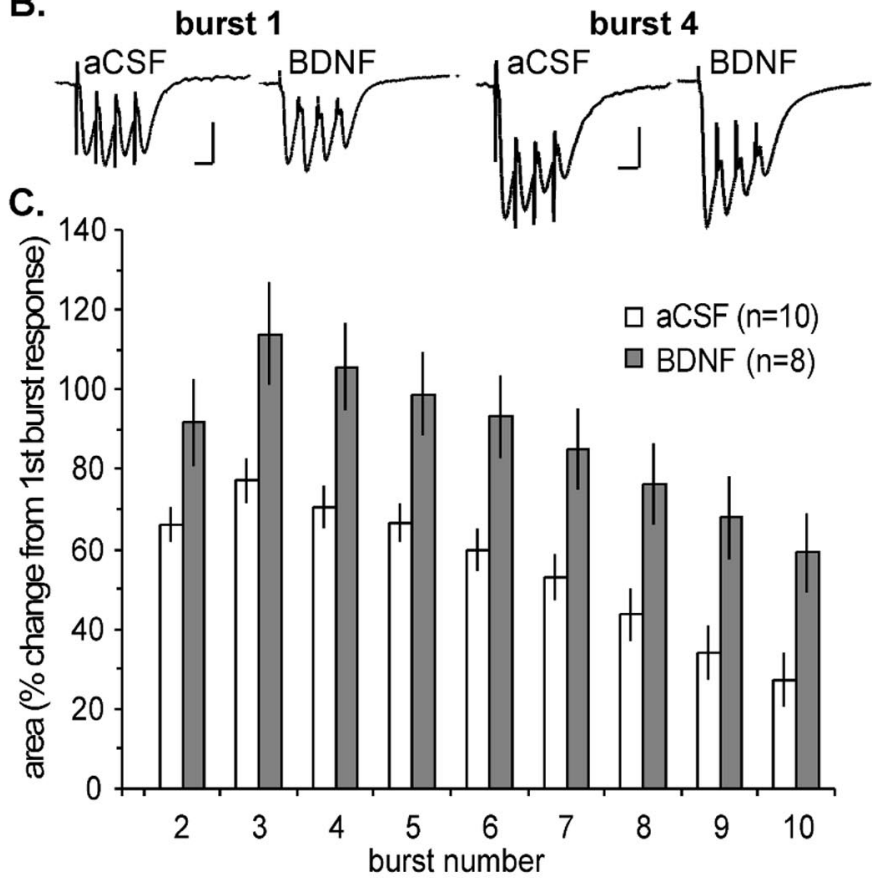

Figure 3. Effects of BDNF on theta-burst responses. $A$, The percentage change in amplitude (relative to the first field EPSP) of the second, third, and fourth field EPSP within a single stimulus train of four pulses at $100 \mathrm{~Hz}$ in control and in $2 \mathrm{~nm}$ BDNF-treated slices (mean \pm SEM). The measures are shown for bursts $1-4$ of a train of 10 theta bursts. The overall shape of the response changes slightly across successive bursts; BDNF did not reliably affect burst topography. $B$, Traces collected after the delivery of the first and fourth theta bursts in control and BDNF-treated slices. Only the initial portions of the 200-msec-long responses are shown. Calibration: $1 \mathrm{mV}, 10 \mathrm{msec}$. C, Percentage increase in response area across a series of 10 theta bursts in control and BDNF-treated slices. Within-train facilitation was significantly greater for each of the nine responses in the BDNF group $(p<0.01)$.

Austria) (Sailer et al., 2002). Antisera were used to probe blots at a 1:500 dilution in Tris-buffered saline including 5\% BSA. In some instances, samples from whole hippocampal homogenates (in RIPA buffer, as above without immunoprecipitation) or lysates of cultured COS7 cells (in RIPA) were processed for PAGE in lanes adjacent to experimental (immunoprecipitation) samples. COS7 lysates have higher total SK2 content than brain homogenates and were used in control experiments to identify the size of SK2-immunoreactive (IR) bands and to demonstrate that SK2-IR bands were eliminated by preabsorption of the antisera with the antigen peptide provided by the vendor. Immunoreactive bands were evaluated by densitometric analysis of films using the AIS image-analysis system (Imaging Research, St. Catherines, Ontario, Canada).

\section{Results}

\section{Baseline transmission and LTP}

BDNF had minimal effects on baseline transmission. The slope of the field EPSP increased slightly over 60 min of infusion, reaching a maximum mean $\pm \mathrm{SD}$ value of $+4 \pm 8.6 \%$ (Fig. $1 A$ ). Previous studies described small and transient increases in slope in a subpopulation of slices (Tanaka et al., 1997; Frerking et al., 1998); the effect appeared to be more consistent in the present experiments. However, the increase in fEPSP slope was accompanied by a significant broadening of the evoked potential (half width, $+5 \pm$ $2.1 \% ; p=0.0002)$. Pretreating slices with the $\mathrm{GABA}_{\mathrm{A}}$ receptor antagonist PTX was used to test the possibility that the effects of BDNF on amplitude and waveform were restricted by feedforward inhibition. The addition of BDNF in the presence of picrotoxin did not cause larger waveform changes, and any effects that it produced in the presence of the antagonist did not indeed reach statistical significance (Fig. $1 \mathrm{~B}$ ). BDNF is reported to cause small decreases in feedforward inhibition (Frerking et al., 1998), and this observation would readily account for the slight broadening of the fEPSP under control conditions (Fig. $1 A$, inset). In all, the observed effects of BDNF on baseline transmission were modest and consistent with previous work (Figurov et al., 1996; Tanaka et al., 1997; Frerking et al., 1998).

Figure $2 \mathrm{~A}$ summarizes the effects of BDNF on LTP induced by a conventional train of 10 theta bursts. The neurotrophin was infused for $60 \mathrm{~min}$ before collecting the $20 \mathrm{~min}$ pre-theta burst baselines in these experiments. The fEPSP slope (percentage from baseline) measured at $30 \mathrm{~min}$ after induction was $+41 \pm 7 \%$ for the control cases and $+75 \pm 24 \%$ for the BDNF-treated slices ( $p<0.01 ; t$ test; two-tailed). Under control conditions, trains of 10 theta bursts are reported to produce the same degree of potentiation as found with 20 bursts (Larson et al., 1986; Arai and Lynch, 1992), and this was confirmed in the present studies (Fig. $2 E)$. Moreover, 20 theta bursts did not increase LTP beyond the value obtained with 10 bursts in BDNF-treated slices (20 theta bursts, $+72 \pm 6.8 \%$ at $30 \mathrm{~min}$ after induction; $p=0.70$ ) (Fig. $2 E)$. Combined with the results described above, this points to the conclusion that BDNF increases the maximum potentiation elicited by TBS. A shorter period of BDNF infusion (i.e., $30 \mathrm{~min}$ ) did not produce significant increases in LTP (data not shown). The stability of LTP was also assessed using 1 min trains of $5 \mathrm{~Hz}$ stimulation, a protocol that erases LTP when applied within $2 \mathrm{~min}$ of induction but is without effect 30 min later (Larson et al., 1993; Staubli and Chun, 1996), in the absence of experimental treatments (Kramár et al., 2003). As shown in Figure 2, $A$ and B, low-frequency trains applied $30 \mathrm{~min}$ after TBS caused an immediate decrease toward baseline in fEPSP slope in both groups of slices, followed by a near complete recovery of potentiation for control (fEPSP slope before TPS, $+41 \pm 7 \%$ vs $30 \mathrm{~min}$ after TPS, $+38 \pm 9 \% ; p=0.9)$ and BDNF-treated (fEPSP slope before TPS, $+75 \pm 23 \%$ vs $30 \mathrm{~min}$ after TPS,$+70 \pm 37 \% ; p=0.09$ ) groups. This experiment establishes that LTP elicited in the presence of BDNF consolidates over the course of $30 \mathrm{~min}$ to approximately the same degree as in control slices. 
A.

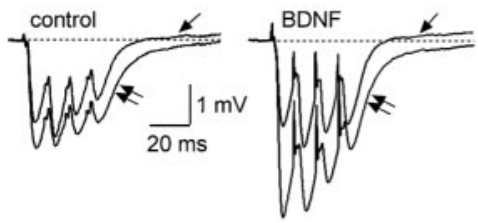

B.

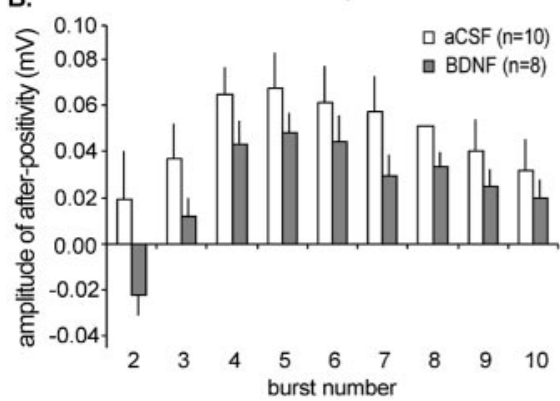

D.
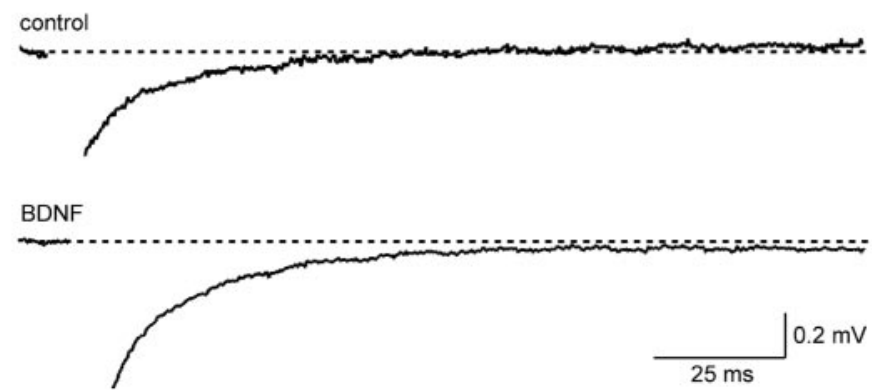

Figure 4. Effects of BDNF on burst-response parameters. $A$, Representative examples of the first 50 msec of the first and fourth (double arrows) burst responses in a theta train. The negative-going component of the response lasts for $\sim 50 \mathrm{msec}$ and is followed by a small positive potential (single arrow) that reaches its maximum at $\sim 200 \mathrm{msec}$ (i.e., immediately before the next response in a train). BDNF increases both the size of the burst response and its duration. $B$, Mean \pm SEM amplitudes of the afterpotential at 200 msec for groups of control and BDNF-treated slices; the amplitude for bursts 2-10 was significantly different in the two groups $(p<0.01)$. C, Comparison of the duration of the burst responses (measured as the time required for the response to return to the prestimulation baseline) in control and BDNF-treated slices. The mean \pm SEM duration of responses across bursts 2-10 was significantly greater in the BDNF group $(p<0.01)$. D, Representative traces of the amplitude of the afterpositivity recorded during the second burst from a control and BDNF-treated slice. Traces depict the baseline and last 150 msec of the recorded response.

The effects of BDNF on LTP threshold are described in Figure 2, $C$ and $D$. A single pair of theta bursts did not reliably induce stable potentiation in control slices but resulted in a significant increase in fEPSP slope in BDNF-treated cases compared with controls ( $30 \mathrm{~min}$ after TBS, $0.0 \pm 6.6 \%$ for controls vs $+13 \pm$ $4.6 \%$ for BDNF; $p<0.01$ ). Results for a suprathreshold but submaximal train of five bursts are summarized in Figure $2 D$. Five bursts caused a small but reliable degree of LTP 30 min after TBS in controls $(+17 \pm 6 \%)$ and a somewhat larger effect in the BDNF-treated slices $(+38 \pm 5 \% ; p=0.003)$. It is of interest that five theta bursts produced approximately half-maximal potentiation in each case; this similarity would arise if the neurotrophin simply increased the size of each increment of LTP generated by successive bursts. Figure $2 E$ summarizes the results obtained from slices receiving different numbers of bursts in the stimulation train.

\section{Changes in individual theta-burst responses}

Potential effects of BDNF on facilitation within a theta burst were assessed by normalizing the amplitudes of the second through the fourth responses to that of the first fEPSP as shown in Figure 3A. In agreement with previous reports (Arai and Lynch, 1992; Bahr et al., 1997), the second of the four fEPSPs in each burst under control conditions was larger than the first, with significant decrements occurring in the third and fourth evoked potentials. The magnitude of these changes varied across experiments, but the pattern was reliable (Fig. 3A). There were no evident differences between the within-burst changes in fEPSPs in control and BDNFtreated slices (Fig. $3 A$ ). This similarity extended to the slight changes in burst topography that occur across successive bursts within the train (Fig. 3B, compare burst responses 1,4).

Figure $3 C$ describes the magnitude (area) of successive burst responses as a fraction of the area of the first burst response. This measure normalizes differences between slices in the area of the first burst, thereby allowing for the detection of any effects that develop during the course of the stimulation train. The pattern of facilitation (increasing and then decreasing) has been described in previous reports (Arai and Lynch, 1992; Bahr et al., 1997) and was not noticeably different for the two groups. However, the growth of the burst responses within a train was increased by $60-100 \%$ over control in the BDNF group, with the largest percentage effect occurring in the later bursts (Fig. $3 C$ ). The mean increase in burst-response area for bursts $2-10$ over burst 1 was $55 \pm$ $16 \%$ for control slices and $88 \pm 29 \%$ for BDNF-treated slices $(p<0.01)$. A similar pattern, with equivalent BDNF versus control differences, was obtained if bursts 2-10 were normalized to the area of the first fEPSP in the initial burst response rather than to the area of the entire first burst (data not shown). In all, BDNF had much larger effects on the within-train facilitation of theta bursts than it did on the topography of individual bursts.

Although amplitude of the field EPSPs is the dominant variable in the area of theta- burst responses, the afterpositivity could also make a contribution (Arai et al., 1994). As shown in Figure $4 \mathrm{~A}$, theta-burst responses in control slices are followed by a positive wave that begins after the fourth fEPSP (afterpositivity) and is near maximal at $200 \mathrm{msec}$, the time point at which the succeeding burst arrives. The absolute amplitude of the afterpositivity, at $100-200$ msec after the burst response, grew larger across successive bursts in parallel with the increase in the area of the burst responses (Figs. 3C, $4 B$, compare open bars). Examination of this relationship in control slices indicated that the afterpositivity correlated with the area of the burst that preceded it in comparisons across bursts $3-10(r=0.66$; $p<0.04$; mean of eight responses). Given these observations, the positive influence of BDNF on burst area would be expected to cause a parallel increase in the amplitude of the afterpositivity. However, as summarized in Figure 4B, BDNF significantly reduced the absolute amplitude of the afterpositivity (bursts $2-10,0.025 \pm 0.02 \mathrm{mV}$ ) relative to controls (bursts $2-10,0.045 \pm 0.05 \mathrm{mV} ; p=0.03$ ). This was associated with a significant increase in the durations of bursts 2-10 (mean percentage change in burst duration for 
control, $180 \pm 5 \%$ vs $212 \pm 9 \%$ for BDNF; $p<0.03$ ) (Fig. 4C,D).

\section{Effects of BDNF on}

\section{calcium-dependent AHPs}

The above pattern of results suggests that BDNF influences a variable that is essentially missing from the first burst in a series but modulates the magnitude (but not the internal organization) of later bursts. The various AHPs set in motion by highfrequency spiking are reasonable candidates for this variable. Whole-cell recording in the presence of the $\mathrm{GABA}_{\mathrm{A}}$ receptor antagonist PTX was used to test this hypothesis. Theta bursts were followed by a large hyperpolarization that reached its maximum at $\sim 200$ msec and then decayed to baseline over the subsequent $2 \mathrm{sec}$ (Fig. 5A, control). Changing the membrane potential to $-90 \mathrm{mV}$ eliminated the post-burst afterpotentials (Fig. 5B). In agreement with previous studies (Schwartzkroin and Stafstrom, 1980; Lynch et al., 1983), the AHPs were greatly reduced in recordings collected with electrodes containing the calcium-chelating agent BAPTA (20 mM) (Fig. 5A). There is good evidence that both the BK-type (fast-activating) and SK-type (medium- and slow-activating) calcium-activated potassium channels contribute to AHPs in forebrain neurons (Sailer et al., 2002; Weiger et al., 2002). In the particular case of field CA1 pyramidal cells, SK2type channels are present in high concentrations and are reported to make a sizeable contribution to local AHPs (Stocker et al., 1999). This was confirmed in the present studies with apamin $(50 \mathrm{nM})$, a toxin that preferentially blocks SK2 channels (Fig. 5C).

To test the effects of BDNF on the AHP, single theta bursts were applied at widely spaced intervals ( $4 \mathrm{~min}$ ) to prevent the interactions that lead to LTP. Under control conditions, the amplitudes (percentage change from baseline) of AHPs that followed individual burst responses were stable across $90 \mathrm{~min}$ or longer (Fig. 5D, top, $E)$. Locally applied BDNF (20 nM) reduced the amplitude of the AHPs as shown in Figure $5 D$ (bottom). This effect was evident within the first $100 \mathrm{msec}$ of the response and was pronounced at 200 and $400 \mathrm{msec}$, suggesting that the neurotrophin influences both medium and slow components of the AHP (Stocker et al., 1999; Shah and Haylett, 2000). Reductions in AHPs developed within 15 min of BDNF infusion, as shown for a group of 10 cells in Figure $5 F(-15 \pm 21 \%$ at 16 min; $p=0.04)$, and then leveled out at $\sim 25 \%$ below baseline over the next 30 min (repeated-measures ANOVA; $p=0.001$ for baseline to 55 min after BDNF application). Longer infusions of BDNF appeared to initiate a second decline in the AHP, as seen for a subgroup of six cells that remained stable for over $1 \mathrm{hr}$ (Fig. 5G). The responses began a second decline at $\sim 1 \mathrm{hr}$ after the start of perfusion, ultimately decreasing to $\sim 80 \%$ below baseline. It is of
B.

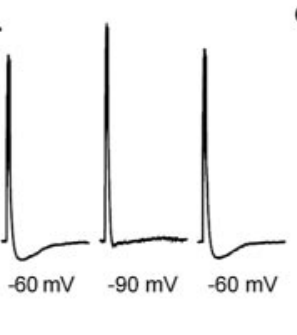

C.

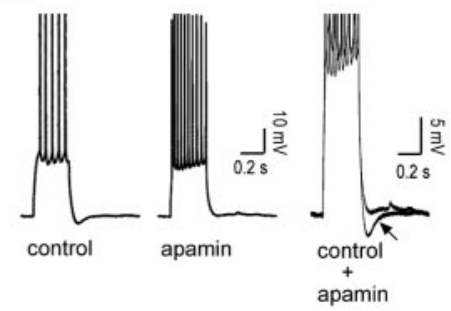

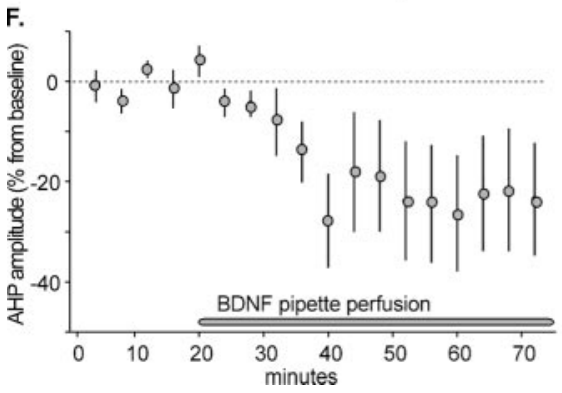

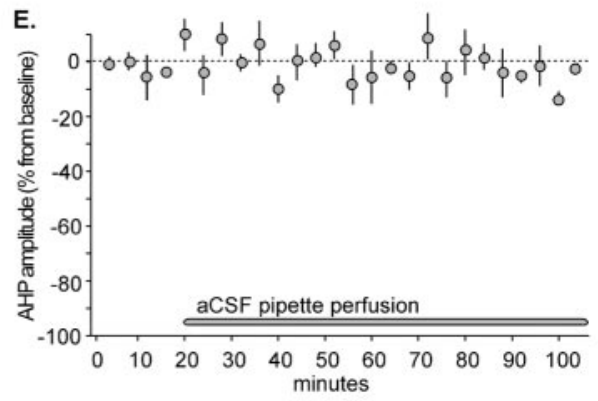

G.

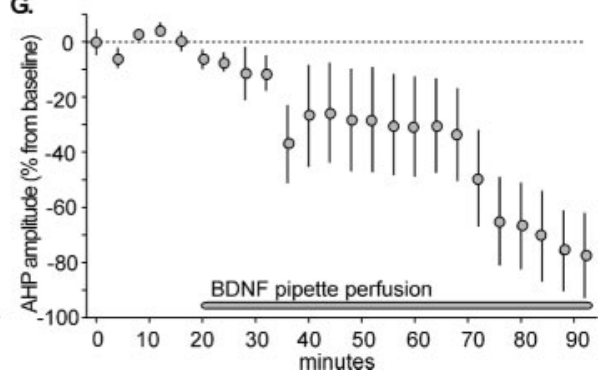

Figure 5. Calcium-dependent AHPs are reduced by BDNF. A, Whole-cell recordings of theta-burst responses collected under control conditions and with electrodes containing the calcium-chelating agent BAPTA $(20 \mathrm{~mm})$. All recordings were made in the $500-1000 \mathrm{msec}$. This afterpotential is greatly reduced in cells sampled with BAPTA electrodes. B, The AHP is reduced when the membrane potential is brought to $-90 \mathrm{mV}$. C, Hyperpolarization is also triggered when brief injections of depolarizing current are markedly reduce this potential, as indicated by the superimposed traces on the right (note that a higher gain was used in displaying these records; the AHP in the control trace is indicated by the arrow). D, Whole-cell recordings collected from contro is from the 70 min time point. The two records are superimposed on the right. In all cases, the responses were initiated by a single applied locally with a perfusion pipette beginning at $20 \mathrm{~min}$ and continued for the duration of the experiment. Theta bursts were treatment was highly significant $(p<0.05)$. G, Summary of data for a subset of six slices in which the clamp was maintained for $70 \mathrm{~min}$ after the start of BDNF application; a late drop in the mean amplitude of the afterpotential is evident.

interest that the small changes in field responses described previously emerged after $\sim 1 \mathrm{hr}$ of treatment with BDNF.

\section{Effects of SK2 channel blockers on theta-burst responses}

The above results raise the possibility that reductions in AHPs, in part generated by SK2-mediated potassium currents, contribute to the enhanced theta bursts produced by BDNF. If so, then apamin would also be expected to increase the area of the burst responses that occur during a theta-burst train. The results illustrated in Figure 6, $A$ and $B$, confirms this prediction. Slices treated with apamin $(50 \mathrm{nM})$ had burst responses that were much larger than those found in control slices, with the change appearing on burst 2 and reaching its greatest magnitude in later bursts. The mean percentage increase in area of bursts $2-10$ over burst 1 for 
A.

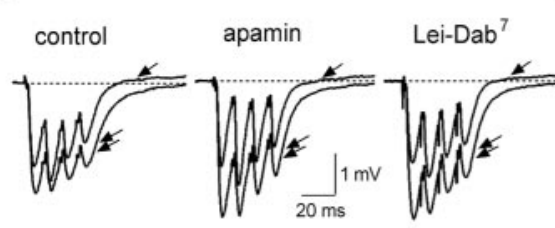

C.

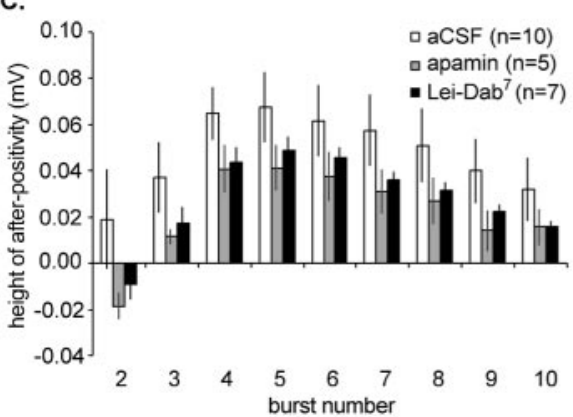

E.

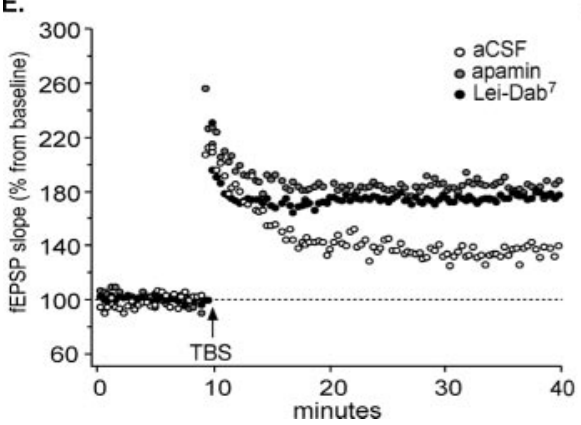

B.

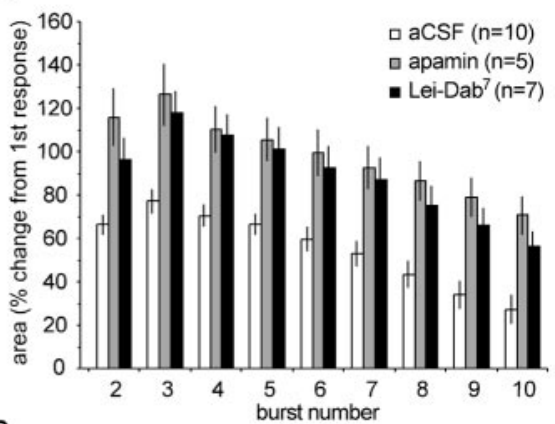

D.

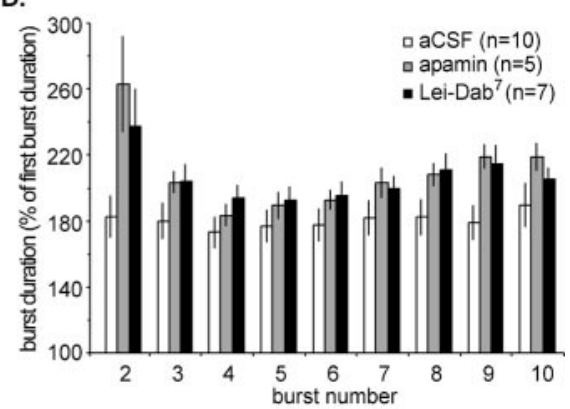

F.

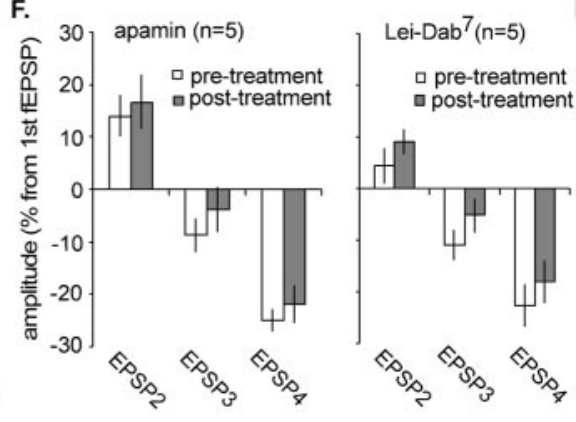

Figure 6. SK2 channel blockers modify theta-burst responses. A, Representative examples of the first (single arrow) and the fourth (double arrows) responses to a train of theta bursts from three groups of slices: control; treated with the SK2 channel toxin apamin (50 nм); and treated with the specific SK2 channel antagonist Lei-Dab ${ }^{7}(100 \mathrm{~nm}) . B$, Apamin and Lei-Dab ${ }^{7}$ significantly increase the facilitation of burst responses that occur within a theta stimulation train relative to controls $(p<0.01)$. Shown are the mean \pm SEM percentage increases in the areas of the responses to bursts $2-10$ relative to the first burst in the train. C, Apamin and Lei-Dab ${ }^{7}$ both reduce the amplitude of the afterpositivity that follows the burst response; measurements were made at 200 msec after the beginning of the theta burst. $D$, The prolongation of burst responses that occur within a theta train is significantly greater in slices infused with apamin or Lei-Dab ${ }^{7}$ than it is in controls $(p<0.01)$. The values shown are mean \pm SEM percentage changes from the duration of the first burst. E, LTP is enhanced in slices treated with $50 \mathrm{~nm}$ apamin or $100 \mathrm{~nm}$ Lei-Dab ${ }^{7}$. Graph shows representative experiments evaluating the effects of apamin and Lei-Dab ${ }^{7}$ on LTP. After a train of 10 theta bursts (TBS, upward arrow), the potentiation leveled off at $\sim 80 \%, 30$ min after LTP induction. This effect is almost double the size of LTP in control slices. $F$, A single theta burst was applied to slices before and 60 min after treatment with $50 \mathrm{~nm}$ apamin or $100 \mathrm{~nm} \mathrm{Lei-Dab}{ }^{7}$. The percentage change in amplitude (relative to the first field EPSP) of the second, third, and fourth field EPSP within the single theta burst in control, $50 \mathrm{~nm}$ apamin-treated, and $100 \mathrm{~nm}$ Lei-Dab ${ }^{7}$-treated slices (mean \pm SEM) is shown. The magnitude of the individual fEPSPs were no different within pretreatment and posttreatment conditions for both apamin- and Lei-Dab ${ }^{7}$-treated slices.

apamin-treated slices was $+98 \pm 23 \%$. This is almost twice the value obtained without the toxin $(p<0.001)$ and approximately the same as that described above for BDNF $(+89 \%)$. Slices infused with apamin also displayed a significant decrease in the mean amplitude of the afterpositivity found between bursts 2-10 (apamin, $0.02 \pm 0.02 \mathrm{mV}$ vs control, $0.05 \pm 0.03 \mathrm{mV} ; p=0.008$ ) and a considerable increase in the duration of individual bursts (mean percentage increase in duration for bursts 2-10, $103 \pm$ $13.4 \%$ for apamin vs $80 \pm 4.5 \%$ for controls; $p=0.003$ ) (Fig. $6 C, D$, respectively). The changes in burst responses were also accompanied by an elevation of the LTP ceiling. Apamin infusions of $50 \mathrm{~min}$ enhanced baseline fEPSP slope by $20 \pm 11 \%$.
Using the augmented responses as a baseline, a train of 10 theta bursts produced a significant increase in fEPSP slope of $+76 \pm 24 \%$ at 30 min after induction compared with $+41 \pm 8 \%$ for controls $(p<0.001)$ (Fig. 6E). Previous studies using other stimulation paradigms have also shown that apamin enhances LTP (Behnisch and Reymann, 1998; Stackman et al., 2002).

Although apamin has a clear preference for SK2 channels, there is evidence that it also affects other calcium-activated potassium channels (Ishii et al., 1997; Shah and Haylett, 2000). Accordingly, a newly introduced SK2 antagonist, Lei-Dab ${ }^{7}$, with a high degree of selectivity for the SK2 channel (Shakkottai et al., 2001) was used to test the conclusion that blocking the SK2 channel increases burst responses and enhances LTP. Lei-Dab ${ }^{7}$ incubations at 100 $\mathrm{nM}$ for $50 \mathrm{~min}$ did not reliably affect the slope of fEPSPs $(3 \pm 4 \%)$, but, as shown in Figure 6, $A$ (far right) and $B$, Lei-Dab $^{7}$ significantly increased the area of theta-burst responses $(+89 \pm 24 \%)$ relative to controls $(+55 \pm 16 \% ; p=0.001)$. Slices treated with Lei-Dab ${ }^{7}$ also displayed a significantly smaller afterpositivity and a marked increase in burst duration compared with control slices $(p=0.001, p=$ 0.01 , respectively) (Fig. 6C,D). These changes in burst-response characteristics for Lei-Dab ${ }^{7}$ were accompanied by a significant increase in LTP $(+77 \pm 25 \%)$ at 30 min after TBS ( $p=0.002$ vs controls) (Fig. 6E).

Although both apamin and Lei-Dab ${ }^{7}$ had pronounced effects on the way in which burst responses grew during a train, they did not detectably affect the first burst in the train. Figure $6 F$ summarizes the within-burst changes for the fEPSPs during burst 1 ; response 2 , but not response 3 , was modestly facilitated over response 1 , whereas response 4 was depressed. These characteristics were still present in apamin- or Lei-Dab ${ }^{7}$-treated slices and in magnitude not detectably different from controls (ANOVA; $p>0.2$ ).

Finally, the parallel effects of the SK2 inhibitors and BDNF across different burst parameters strongly suggest that the different compounds operate on a common endpoint. If so, then the combined effects of the neurotrophin and inhibitor should be no greater than the effect obtained with either alone. Results of a test of this point using BDNF and apamin are summarized in Figure 7. Increases in burst-response area (Fig. $7 A$ ) were virtually identical for the combined treatment relative to that obtained with BDNF alone, as were the increases in burst duration (Fig. $7 B$ ) and the magnitude of LTP (Fig. 7D). The reduction (from control values) of the amplitude of the afterpositivity (Fig. 7C) tended to be greater with the combined treatment than with BDNF alone, but this effect did not approach statistical 
significance. It should be noted that other treatments that increase theta bursts (e.g., positive modulators of AMPA-type glutamate receptors) (Arai et al., 2004) add to the effects of BDNF, resulting in responses substantially larger than those described here. Therefore, the absence of an additive effect between BDNF and apamin in the present experiments does not appear to be attributable to a ceiling on the size of the response measure but instead constitutes evidence that the two treatments act on a final common pathway to promote within-train facilitation of theta bursts.

\section{BDNF triggers the phosphorylation of SK2 potassium channels}

AHP currents are known to include fast, medium, and slow components that are attributable to different classes of potassium channels; large-conductance, calciumactivated potassium (BK) channels account for fast and medium responses, whereas small-conductance, calcium-activated SK channels account for medium (apamin-sensitive) and slow aspects of the response (Sailer et al., 2002; Weiger et al., 2002). BDNF binding to TrkB initiates a variety of signaling cascades (Patapoutian and Reichardt, 2001) that in some instances include serine kinases that recognize calcium-dependent potassium channels (Holm et al., 1997; Rogalski et al., 2000; Tian et al., 2001; Weiger et al., 2002). Because this provides a route through which BDNF could exert its above-described influence on AHPs, the effects of BDNF treatment on serine phosphorylation of SK2 protein were evaluated.

Figure 8, $A$ and $B$, shows immunoblots of homogenates from BDNF-treated and control hippocampal slices that had been immunoprecipitated with anti-phosphoserine and then probed for SK2 immunoreactivity; the blots in $A$ and $B$ were processed with the normal SK2 antiserum compared with anti-SK2 that had been preabsorbed with the antigen peptide provided by the vendor, respectively. As seen in Figure $8 A$, in control hippocampal homogenate (lane 1), immunoreactive bands are present at $>250$ $\mathrm{kDa}$, at slightly less than $160 \mathrm{kDa}$, at $\sim 105 \mathrm{kDa}$, and at $45-50 \mathrm{kDa}$ overlying the large deposition of heavy chain IgG at the bottom of the gel. The lower bands, at $105 \mathrm{kDa}$ and at $45-50 \mathrm{kDa}$, correspond with sharp bands of SK2 immunoreactivity within straight Western blots of COS7 cell lysates (Fig. 8A, lanes 3, 4) and hippocampal homogenates (data not shown). When blots were probed with antigen-preabsorbed antibody (Fig. $8 \mathrm{~B}$ ), the density of these bands was markedly reduced in immunoblots of phosphoserine precipitates from hippocampal homogenates and eliminated in blots of COS7 cell lysates. In contrast, preabsorption did not reliably affect the densities of the larger (upper) immunoreactive bands, suggesting that they represent crossreactivity with non-SK2 proteins.

As shown in Figure $8 \mathrm{~A}$ (lane 2), BDNF treatment markedly increased the abundance of serine-phosphorylated SK2 immunoreactivity at 105 and $45-50 \mathrm{kDa}$ (i.e., Fig. $8 \mathrm{~A}$, bottom dash). The enhanced SK2 immunoreactivity within both bands was eliminated by antisera preabsorption with SK2 antigen (Fig. 8 B).

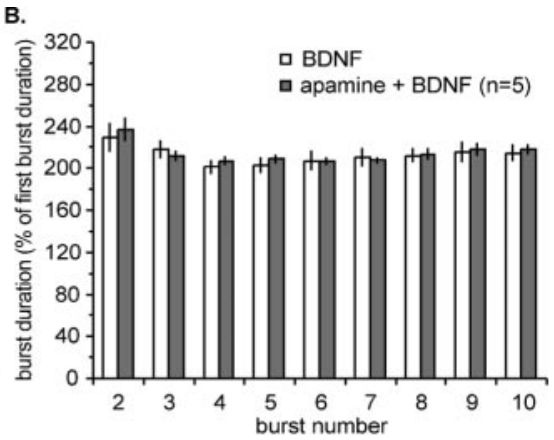

口BDFF

a apamin + BDNF $(n=5)$

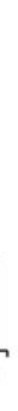

D.
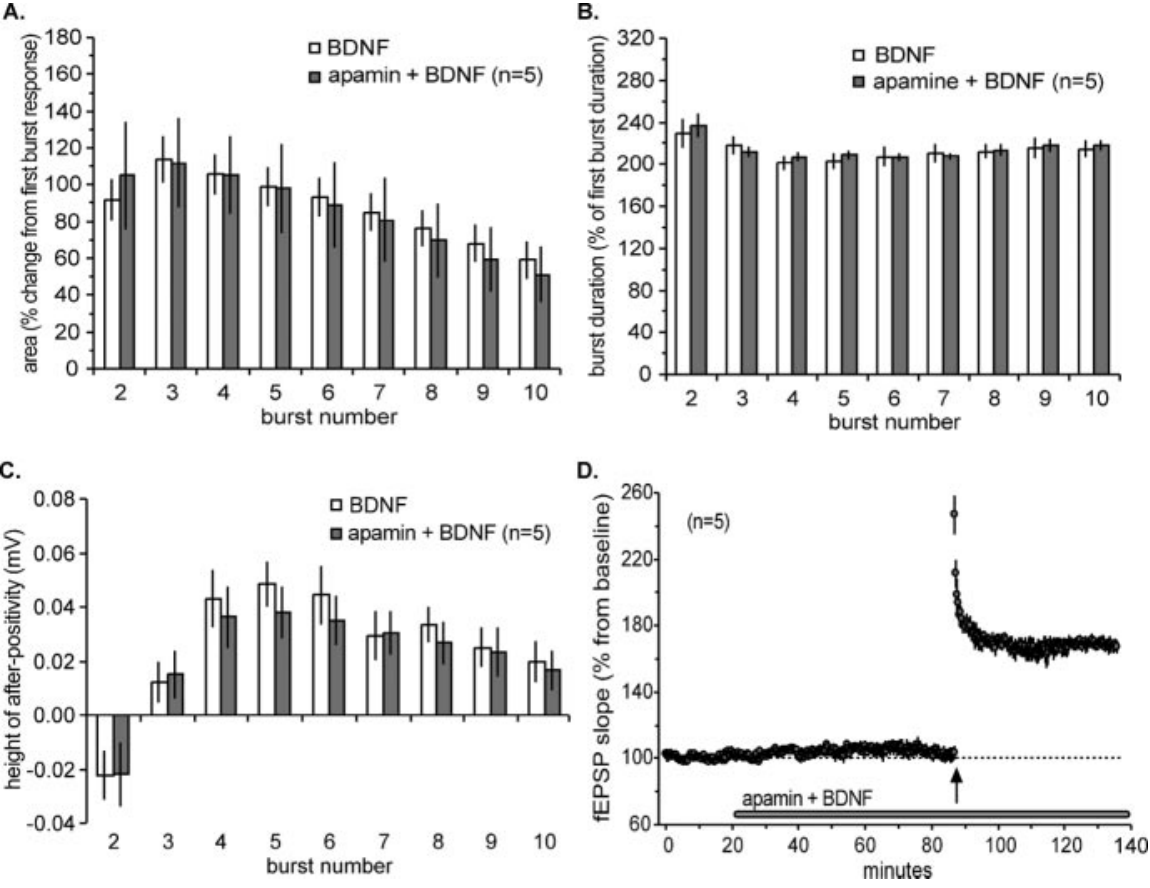

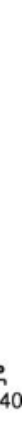

Figure 7. Effects of a combination of apamin and BDNF on LTP and theta-burst responses. A, Slices treated with BDNF ( $2 \mathrm{~nm})$ (1) for 60 min before and after TBS had equivalent increases in the size of burst responses during ANOVA). D, TBS (arrow) produced a robust LTP in slices treated with BDNF plus apamin. Potentiation at 50 min after TBS stabilized

The larger molecular weight $(>105 \mathrm{kDa})$ immunostained bands were not affected by BDNF treatment. Comparable results were obtained in three experiments. In two experiments, with antiphosphoserine precipitates probed with anti-SK2 from Alomone Labs, the $105 \mathrm{kDa}$ band was 72 and 59\% more dense in BDNFtreated samples compared with control samples. In a third experiment using anti-SK2 from Knaus and colleagues (Sailer et al., 2002), the $105 \mathrm{kDa}$ band was 25\% more dense with BDNF treatment.

BDNF-induced changes in levels of serine phosphorylated SK2 immunoreactivity were not accompanied by changes in total SK2 immunoreactivity. Immunoprecipitation of hippocampal homogenates with anti-SK2 followed by Western blots probed with anti-SK2 yielded just one immunoreactive doublet at $\sim 105$ $\mathrm{kDa}$; this SK2-IR doublet was of comparable density in control and BDNF-treated samples (Fig. 8C).

\section{Discussion}

The present results confirm previous reports that exogenous BDNF facilitates the induction of LTP. The use of different variants of the theta-burst paradigm established that the neurotrophin lowered the induction threshold and increased the maximum degree of potentiation elicited by trains of bursts. Previous studies have shown that the first of these effects, but not the second, can be produced by increasing the amplitude of synaptic responses, through either increased neurotransmitter release or enhanced postsynaptic responses (Arai and Lynch, 1992). It is unlikely that such effects were responsible for the increased potentiation described here. BDNF had minimal effects on the size of single synaptic responses, and these were qualitatively similar 


\section{IP: phosphoserine}

WB: SK2
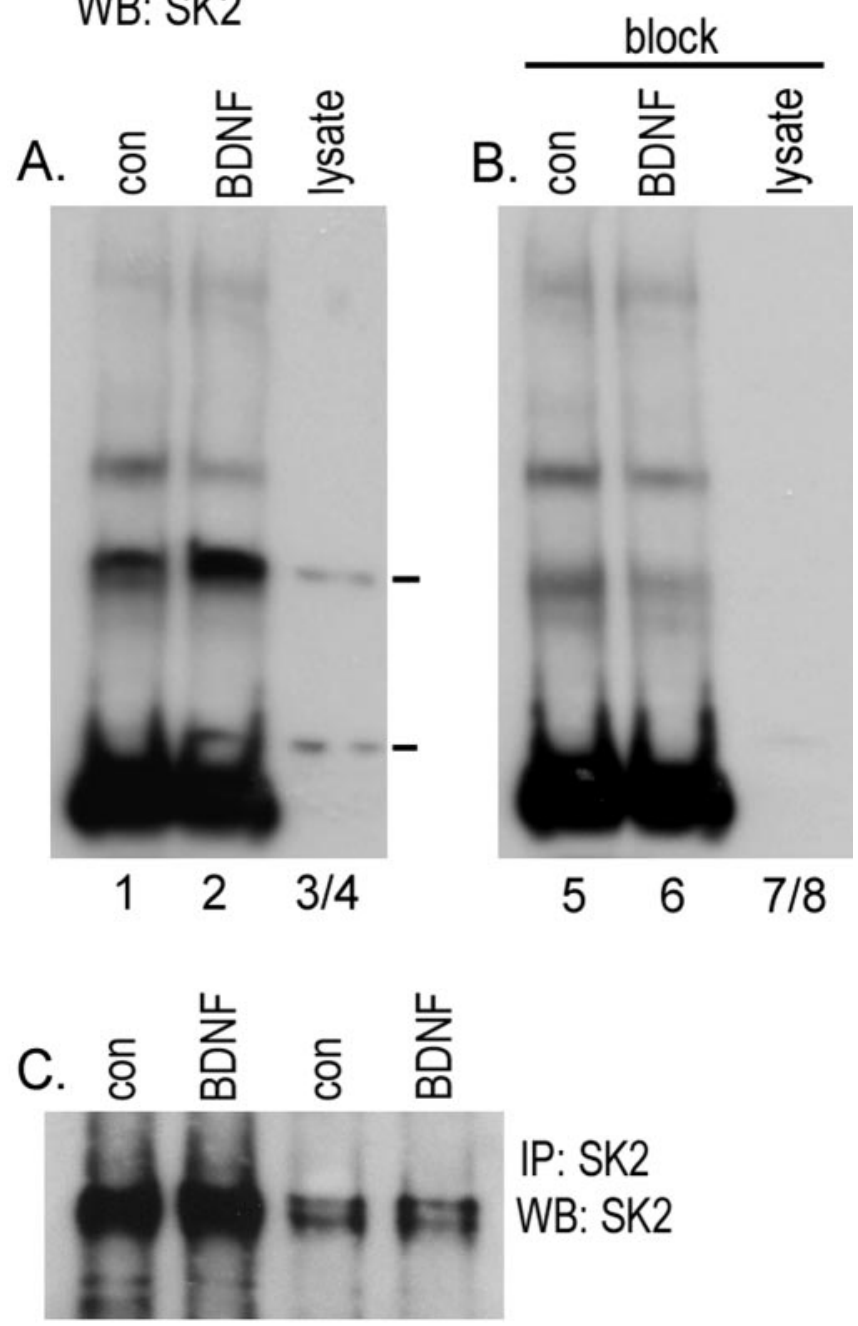

Figure 8. BDNF treatment increases SK2 serine phosphorylation. $A$, $B$, Western blots of (1) phosphoserine immunoprecipitates from homogenates of control (con) and BDNF-treated hippocampal slices (lanes $1,2,5,6)$ and (2) COS7 cell lysates (lanes 3/4,7/8) that had been probed with intact anti-SK2 (Alomone Labs) ( $A$ ) or anti-SK2 that had been preabsorbed with antigen peptide (B). As seen in $A$, two sharp bands of SK2 immunoreactivity within the COS7 lysate (lanes $3 / 4$; at 105 and $45-50 \mathrm{kDa}$ ) correspond with phosphoprotein bands in the hippocampal homogenates that become markedly more robust with BDNF treatment. $B$ shows that antigenpreabsorbed antibody no longer detects (1) these bands in the COS7 lysate or (2) enhanced phosphoserine immunoreactivity at these molecular weights in samples of BDNF-treated hippocampal tissue. C, Western blot of SK2 immunoprecipitates from homogenates of control and BDNF-treated slices that were probed with anti-SK2 (Alomone Labs) show that BDNF does not influence levels of total SK2 immunoreactivity; the two lanes at left and right were loaded with 30 and $10 \mu$ l of sample, respectively. IP, Immunoprecipitates; WB, whole brain.

to the changes produced by low concentrations of $\mathrm{GABA}_{\mathrm{A}}$ receptor antagonists. This accords with work showing that BDNF reduces hippocampal IPSPs (Frerking et al., 1998). BDNF also affects the capacity of synapses in developing hippocampus to follow high-frequency stimulation (Gottschalk et al., 1998). In the present study, BDNF did not measurably alter the changes in individual field EPSPs that occur within the second and subsequent bursts within a theta train. This indicates that a factor in addition to enhanced frequency-following contributes to the effects of the neurotrophin on LTP.

The facilitation of theta-burst responses that occurs over the course of a theta train was markedly enhanced by BDNF. The increase in the area and duration of the burst was accompanied by a reduction in the absolute amplitude of the slow positive response that follows the bursts. The greater than normal depolarization with attendant effects on NMDA receptors on the second burst explains how a single pair of theta bursts administered in the presence of BDNF elicits robust LTP (i.e., the lower LTP threshold). Regarding the mechanisms responsible for enhanced burst responses, transmission dynamics in the later responses were not markedly changed because within-burst facilitation of fEPSPs was similar to control in between-group comparisons. An alternative is that BDNF changes burst-response parameters through effects on the long-duration AHPs initiated by individual burst responses. Whole-cell recordings confirmed that BDNF reduces the size of the calcium-dependent AHP that follows theta bursts. This represents a previously unrecognized effect of the neurotrophin and one that logically relates to its effects on theta burst-induced LTP. That is, previous studies have shown that suppressing the AHP both lowers the threshold and raises the ceiling for LTP in CA1 pyramidal cells (Arai and Lynch, 1992; Arai et al., 1994; Sah and Bekkers, 1996; Stackman et al., 2002).

The AHP recorded in CA1 pyramidal cells is strongly blocked by calcium-chelating agents. High concentrations of SK channels are found in hippocampal neurons, and a combination of these channels generates a composite AHP with slow, medium, and fast components. The SK2 channel is among those expressed at high concentrations in CA1 pyramidal cells and makes a significant contribution to the AHP, as indicated by the results obtained with apamin (Stocker et al., 1999), which preferentially blocks SK2 function. This observation allowed an additional test of the idea that reductions in AHPs enhance theta-burst responses. Apamin reproduced each of the effects of BDNF on burst responses and, as reported previously (Behnisch and Reymann, 1998; Stackman et al., 2002), enhanced LTP. Apamin also had significant effects on baseline responses but these were absent in slices treated with the recently introduced and highly selective SK2 antagonist Lei$\mathrm{Dab}^{7}$. Despite this, the antagonist increased theta-burst responses and enhanced LTP.

The results obtained with apamin and Lei-Dab ${ }^{7}$ point to the specific hypothesis that BDNF, at least in part, enhances thetaburst responses by reducing SK2 conductance. As predicted from this conclusion, combining BDNF and apamin had no greater effect on theta bursts or LTP than either alone. How the neurotrophin might exert its effects are unclear. Little is known about modulation of SK2 in the adult hippocampus but there is evidence that it (Lu and Wang, 1996; Kong et al., 2000; Lu et al., 2002), along with other potassium channels (Levitan, 1994; Hall and Armstrong, 2000; Rogalski et al., 2000), is regulated by phosphorylation. Given that BDNF initiates signaling cascades that in some instances include kinases that recognize potassium channels (Holm et al., 1997; Hoffman and Johnston, 1998; Rogalski et al., 2000; Gallo et al., 2002; Yuan et al., 2002), phosphorylation constitutes a potential link between the neurotrophin and the reduction in AHPs. In support of this, the same BDNF treatments that reduced the AHP and enhanced theta-burst responses increased serine phosphorylation of SK2 channels. MAPK (mitogen-activated protein kinase) has been shown recently to phosphorylate the Kv4 domain of voltage-sensitive potassium channels in apical dendrites of field CA1 via activation of protein kinases A and C (Yuan et al., 2002). The latter kinases recognize SK2 (Lu and Wang, 1996; Lu et al., 2002) and provide plausible effectors for the observed biochemical and physiological effects of BDNF.

The link between BDNF and theta bursts may be reciprocal in that the latter trigger the rapid release of the neurotrophin from 
presynaptic terminals (Balkowiec and Katz, 2002). This effect is most probably too slow to affect the 10 burst $(2 \mathrm{sec})$ trains used to induce LTP but, from the present results, would amplify trains of two or more bursts occurring minutes afterward. Assuming that the highest BDNF concentrations occur near release sites, then theta bursts would have the effect of priming (through AHP reduction) their target neurons for the induction of LTP by subsequent bursts. This could relate to the common observation that memory in many paradigms is best encoded with significant delays between acquisition sessions. In any event, it will be of interest to test whether the time course for the effects of BDNF on theta bursts predicts an optimal spacing of weak theta trains in the production of stable LTP.

\section{References}

Akaneya Y, Tsumoto T, Kinoshita S, Hatanaka H (1997) Brain-derived neurotrophic factor enhances long-term potentiation in rat visual cortex. J Neurosci 17:6707-6716.

Ambros-Ingerson J, Granger R, Lynch G (1990) Simulation of paleocortex performs hierarchical clustering. Science 247:1344-1348.

Aoki C, Wu K, Elste A, Len G, Lin S, McAuliffe G, Black IB (2000) Localization of brain-derived neurotrophic factor and TrkB receptors to postsynaptic densities of adult rat cerebral cortex. J Neurosci Res 59:454-463.

Arai A, Lynch G (1992) Factors regulating the magnitude of long-term potentiation induced by theta pattern stimulation. Brain Res 598:173-184.

Arai A, Black J, Lynch G (1994) Origins of the variations in long-term potentiation between synapses in the basal versus apical dendrites of hippocampal neurons. Hippocampus 4:1-10.

Arai AC, Xia YF, Suzuki E (2004) Modulation of AMPA receptor kinetics differentially influences synaptic plasticity in the hippocampus. Neuroscience 123:1011-1024.

Bahr BA, Staubli U, Xiao P, Chun D, Ji ZX, Esteban ET, Lynch G (1997) Arg-Gly-Asp-Ser-selective adhesion and the stabilization of long-term potentiation: pharmacological studies and the characterization of a candidate matrix receptor. J Neurosci 17:1320-1329.

Balkowiec A, Katz DM (2002) Cellular mechanisms regulating activitydependent release of native brain-derived neurotrophic factor from hippocampal neurons. J Neurosci 22:10399-10407.

Behnisch T, Reymann KG (1998) Inhibition of apamin-sensitive calcium dependent potassium channels facilitate the induction of long-term potentiation in the CA1 region of rat hippocampus in vitro. Neurosci Lett 253:91-94.

Carpenter G, Milenova B (2002) Redistribution of synaptic efficacy supports stable pattern learning in neural networks. Neural Comput 14:873-888.

Chen G, Kolbeck R, Barde YA, Bonhoeffer T, Kossel A (1999) Relative contribution of endogenous neurotrophins in hippocampal long-term potentiation. J Neurosci 19:7983-7990.

Cheng Q, Yeh HH (2003) Brain-derived neurotrophic factor attenuates mouse cerebellar granule cell GABA(A) receptor-mediated responses via postsynaptic mechanisms. J Physiol (Lond) 548:711-721.

Crozier RA, Black IB, Plummer MR (1999) Blockade of NR2B-containing NMDA receptors prevents BDNF enhancement of glutamatergic transmission in hippocampal neurons. Learn Mem 6:257-266.

Desai R, Peretz A, Idelson H, lazarovici P, Attali B (2000) $\mathrm{Ca}^{2+}$-activated $\mathrm{K}^{+}$channels in human leukemic Jurkat $\mathrm{T}$ cells. J Biol Chem 275:39954-39963.

Di Luca M, Gardoni F, Finardi A, Pagliardini S, Cattabeni F, Battaglia G, Missale C (2001) NMDA receptor subunits are phosphorylated by activation of neurotrophin receptors in PSD of rat spinal cord. NeuroReport 12:1301-1305.

Figurov A, Pozzo-Miller LD, Olafsson P, Wang T, Lu B (1996) Regulation of synaptic responses to high-frequency stimulation and LTP by neurotrophins in the hippocampus. Nature 381:706-709.

Frerking M, Malenka RC, Nicoll RA (1998) Brain-derived neurotrophic factor (BDNF) modulates inhibitory, but not excitatory, transmission in the CA1 region of the hippocampus. J Neurophysiol 80:3383-3386.

Gallo G, Ernst A, McLoon S, Letourneau P (2002) Transient PKA activity is required for initiation but not maintenance of BDNF-mediated protection from nitric oxide-induced growth-cone collapse. J Neurosci 22:5016-5023.
Gottschalk W, Pozzo-Miller LD, Figurov A, Lu B (1998) Presynaptic modulation of synaptic transmission and plasticity by brain-derived neurotrophic factor in the developing hippocampus. J Neurosci 18:6830-6839.

Hall SK, Armstrong DL (2000) Conditional and unconditional inhibition of calcium-activated potassium channels by reversible protein phosphorylation. J Biol Chem 275:3749-3754.

Hoffman DA, Johnston D (1998) Downregulation of transient $\mathrm{K}^{+}$channels in dendrites of hippocampal CA1 pyramidal neurons by activation of PKA and PKC. J Neurosci 18:3521-3528.

Holm NR, Christophersen P, Olesen SP, Gammeltoft S (1997) Activation of calcium-dependent potassium channels in rat brain neurons by neurotrophin-3 and nerve growth factor. Proc Natl Acad Sci USA 94:1002-1006.

Huber KM, Sawtell NB, Bear MF (1998) Brain-derived neurotrophic factor alters the synaptic modification threshold in visual cortex. Neuropharmacology 37:571-579.

Ishii TM, Maylie J, Adelman JP (1997) Determinants of apamin and D-tubocurarine block in SK potassium channels. J Biol Chem 272:23195-23200.

Kang HJ, Welcher AA, Shelton D, Schuman EM (1997) Neurotrophins and time: different roles for TrkB signaling in hippocampal long-term potentiation. Neuron 19:653-664.

Kong I, Koh S, Bayguinov O, Sanders K (2000) Small conductance $\mathrm{Ca}^{2+}$ activated $\mathrm{K}^{+}$channels are regulated by $\mathrm{Ca}^{2+}$-calmodulin-dependent protein kinase II in murine colonic myocytes. J Physiol (Lond) 524:331-337.

Korte M, Carroll P, Wolf E, Brem G, Thoenen H, Bonhoeffer T (1995) Hippocampal long-term potentiation is impaired in mice lacking brainderived neurotrophic factor. Proc Natl Acad Sci USA 92:8856-8860.

Korte M, Griesbeck O, Gravel C, Carroll P, Staiger V, Thoenen H, Bonhoeffer $\mathrm{T}$ (1996) Virus-mediated gene transfer into hippocampal CA1 region restores long-term potentiation in brain-derived neurotrophic factor mutant mice. Proc Natl Acad Sci USA 93:12547-12552.

Kossel AH, Cambridge SB, Wagner U, Bonhoeffer T (2001) A caged Ab reveals an immediate/instructive effect of BDNF during hippocampal synaptic potentiation. Proc Natl Acad Sci USA 98:14702-14707.

Kovalchuk Y, Hanse E, Kafitz K, Konnerth A (2002) Postsynaptic induction of BDNF-mediated long-term potentiation. Science 295:1729-1734.

Kramár EA, Bernard JA, Gall CM, Lynch G (2002) Alpha3 integrin receptors contribute to the consolidation of long term potentiation. Neuroscience 110:29-39.

Larson J, Wong D, Lynch G (1986) Patterned stimulation at the theta frequency is optimal for the induction of hippocampal long-term potentiation. Brain Res 368:347-350.

Larson J, Xiao P, Lynch G (1993) Reversal of LTP by theta frequency stimulation. Brain Res 600:97-102.

Levine ES, Kolb JE (2000) Brain-derived neurotrophic factor increases activity of NR2B-containing $N$-methyl-D-aspartate receptors in excised patches from hippocampal neurons. J Neurosci Res 62:357-362.

Levitan IB (1994) Modulation of ion channels by phosphorylation and dephosphorylation. Annu Rev Physiol 56:193-212.

Lin SY, Wu K, Levine ES, Mount HTJ, Cuen PC, Black IB (1998) BDNF acutely increases tyrosine phosphorylation of the NMDA receptor subunit $2 \mathrm{~B}$ in cortical and hippocampal postsynaptic densities. Mol Brain Res 55:20-27.

Lu M, Wang W (1996) Protein kinase C stimulates the small-conductance $\mathrm{K}^{+}$channel in the basolateral membrane of the CCD. Am J Physiol 271:F1045-F1051.

Lu M, Wang T, Yan Q, Yang X, Dong K, Knepper M, Wang W, Giebisch G, Shull G, Hebert S (2002) Absence of small conductance $\mathrm{K}^{+}$channel (SK) activity in apical membranes of thick ascending limb and cortical collecting duct in ROMK (Bartter's) knockout mice. J Biol Chem 277:37881-37887.

Lynch G, Larson J, Kelso S, Barrionuevo G, Schottler F (1983) Intracellular injections of EGTA block induction of hippocampal long-term potentiation. Nature 305:719-721.

Manabe T (2002) Does BDNF have pre- or postsynaptic targets? Science 295:1651-1653.

Patapoutian A, Reichardt LF (2001) Trk receptors: mediators of neurotrophin action. Curr Opin Neurobiol 11:272-280.

Patterson SL, Abel T, Deuel TA, Martin KC, Rose JC, Kandel ER (1996) 
Recombinant BDNF rescues deficits in basal synaptic transmission and hippocampal LTP in BDNF knockout mice. Neuron 16:1137-1145.

Pozzo-Miller LD, Gottschalk W, Zhang L, McDermott K, Du J, Gopalakrishnan R, Oho C, Sheng ZH, Lu B (1999) Impairments in high-frequency transmission, synaptic vesicle docking, and synaptic protein distribution in the hippocampus of BDNF knock-out mice. J Neurosci 19:4972-4983.

Rogalski SL, Appleyard SM, Pattillo A, Terman GW, Chavkin C (2000) TrkB activation by brain-derived neurotrophic factor inhibits the $G$ protein-gated inward rectifier Kir3 by tyrosine phosphorylation of the channel. J Biol Chem 275:25082-25088.

Sah P, Bekkers J (1996) Apical dendritic location of slow afterhyperporlarization current in hippocampal pyramidal neurons: implications for the integration of long-term potentiation. J Neurosci 16:4537-4542.

Sailer CA, Walter HH, Kaufmann A, Trieb M, Schwarzer C, Storm JF, Knaus HG (2002) Regional differences in distribution and functional expression of small-conductance $\mathrm{Ca}^{2+}$-activated $\mathrm{K}^{+}$channels in rat brain. J Neurosci 22:9698-9707.

Schwartzkroin PA, Stafstrom CE (1980) Effects of EGTA on the calciumactivated afterhyperpolarization in hippocampal CA3 pyramidal cells. Science 210:1125-1126.

Shah M, Haylett DG (2000) The pharmacology of hSK1 Ca ${ }^{2+}$-activated $\mathrm{K}^{+}$ channels expressed in mammalian cell lines. Br J Pharmacol 129:627-630.

Shakkottai V, Regaya I, Wulff H, Fajloun Z, Tomita H, Fathallah M, Cahalan M, Gargus J, Sabatier J, Chandy KG (2001) Design and characterization of the highly selective peptide inhibitor of the small conductance calciumactivated $\mathrm{K}^{+}$channel, SkCa2. J Biol Chem 276:43145-43151.

Song DK, Choe B, Bae JH, Park WK, Han IS, Ho WK, Earm YE (1998) Brain-derived neurotrophic factor rapidly potentiates synaptic transmis- sion through NMDA, but suppresses it through non-NMDA receptors in rat hippocampal neuron. Brain Res 799:176-179.

Stackman RW, Hammond RS, Linardatos E, Gerlach A, Maylie J, Adelman JP, Tzounopoulos T (2002) Small conductance $\mathrm{Ca}^{2+}$-activated $\mathrm{K}^{+}$channels modulate synaptic plasticity and memory encoding. J Neurosci 22:10163-10171.

Staubli U, Chun D (1996) Factors regulating the reversibility of long-term potentiation. J Neurosci 16:853-860.

Stocker M, Krause M, Pedarzani P (1999) An apamin-sensitive $\mathrm{Ca}^{2+}$ activated $\mathrm{K}^{+}$current in hippocampal pyramidal neurons. Proc Natl Acad Sci USA 96:4662-4667.

Tanaka T, Saito H, Matsuki N (1997) Inhibition of $\mathrm{GABA}_{\mathrm{A}}$ synaptic responses by brain-derived neurotrohic factor (BDNF) in rat hippocampus. J Neurosci 17:2959-2966.

Tian L, Duncan RR, Hannond MS, Coghill LS, Wen H, Rusinova R, Clark AG, Levitan IB, Shipston MJ (2001) Alternative splicing switches potassium channel sensitivity to protein phosphorylation. J Biol Chem 276:7717-7720.

Weiger TM, Hermann A, Levitan IB (2002) Modulation of calciumactivated potassium channels. J Comp Physiol [A] 188:79-87.

Xu B, Gottschalk W, Chow A, Wilson RI, Schnell E, Zang K, Wang D, Nicoll RA, Lu B, Reichardt LF (2000) The role of brain-derived neurotrophic factor receptors in the mature hippocampus: modulation of long-term potentiation through a presynaptic mechanism involving TrkB. J Neurosci 20:6888-6897.

Yuan L, Adams JP, Swank M, Sweatt JD, Johnston D (2002) Protein kinase modulation of dendritic $\mathrm{K}^{+}$channels in hippocampus involves a mitogen-activated protein kinase pathway. J Neurosci 22:4860-4868. 